\title{
Overexpression of AT2R in the solitary-vagal complex improves baroreflex in the spontaneously hypertensive rat
}

\author{
Prashant J. Ruchaya ${ }^{a}$, Guilherme F. Speretta ${ }^{a}$, Graziela Torres Blanch ${ }^{\text {a }}$, Hongwei Li ${ }^{\text {b }}$, Colin Sumners ${ }^{c}$, \\ José V. Menani ${ }^{a}$, Eduardo Colombari ${ }^{\mathrm{a}, *, 1}$, Débora S.A. Colombari ${ }^{\mathrm{a}, *, 1}$ \\ a Department of Physiology and Pathology, School of Dentistry, São Paulo State University, Araraquara, SP, Brazil \\ b School of Biotechnology, Southern Medical University, Guangzhou, China \\ ' Department of Physiology and Functional Genomics and McKnight Brain Institute, College of Medicine, University of Florida, Gainesville, FL, USA
}

\section{A R T I C L E I N F O}

\section{Article history:}

Received 11 March 2016

Received in revised form 20 May 2016

Accepted 5 June 2016

Available online 20 July 2016

\section{Keywords:}

Hypertension

ACE2

Baroreflex

Angiotensin II

Angiotensin receptor

NTS

\begin{abstract}
A B S T R A C T
The aim of this study was to investigate the physiological effects of increased angiotensin II type 2 receptor (AT2R) expression in the solitary-vagal complex (nucleus of the solitary tract/dorsal motor nucleus of the vagus; NTS/DVM) on baroreflex function in non-anaesthetised normotensive (NT) and spontaneously hypertensive rats (SHR). Ten week old NT Holtzman and SHR were microinjected with either an adeno-associated virus expressing AT2R (AAV2-CBA-AT2R) or enhanced green fluorescent protein (control; AAV2-CBA-eGFP) into the NTS/DVM. Baroreflex and telemetry recordings were performed on four experimental groups: 1) NTeGFP, 2) NTAT2R, 3) SHReGFP and 4) SHRAT2R ( $n=4-7$ /group). Following in-vivo experimental procedures, brains were harvested for gene expression analysis. Impaired bradycardia in SHReGFP was restored in SHR rats overexpressing AT2R in the NTS/DMV. mRNA levels of angiotensin converting enzyme decreased and angiotensin converting enzyme 2 increased in the NTS/DMV of SHRAT2R compared to SHReGFP. Increased levels of proinflammatory cytokine mRNA levels in the SHReGFP group also decreased in the SHRAT2R group. AT2R overexpression did not elicit any significant change in mean arterial pressure (MAP) in all groups from baseline to 4 weeks post viral transfection. Both SHReGFP and SHRAT2R showed a significant elevation in MAP compared to the NTeGFP and NTAT2R groups. Increased AT2R expression within the NTS/DMV of SHR was effective at improving baroreflex function but not MAP. We propose possible mediators involved in improving baroreflex are in the ANG II/ACE2 axis, suggesting a potential beneficial modulatory effect of AT2R overexpression in the NTS/DMV of neurogenic hypertensive rats.
\end{abstract}

(c) 2016 Elsevier Ltd. All rights reserved.

\section{Introduction}

Neurogenic hypertension is a chronic disease involving a myriad of factors resulting in the phenotypic elevation in sympathetic nerve activity (SNA) and blood pressure (BP) (Primatesta and Poulter, 2006). Hypertension is a condition that leads to the predisposition of cardiovascular diseases such as heart failure and stroke. The spontaneously hypertensive rat (SHR) displays an increased sympathetic tone (Trippodo and Frohlich, 1981) making it an appropriate model for investigating essential hypertension. Characteristically, SHR exhibit a hyperactive renin-angiotensin system (RAS), including higher angiotensin II (ANG II) levels and turnover in several brain areas [reviewed

\footnotetext{
* Corresponding authors at: Department of Physiology \& Pathology, School of Dentistry of Araraquara, UNESP, Rua Humaitá, 1680, Araraquara 14801-903, SP, Brazil.

E-mail addresses: eduardo.colombari@foar.unesp.br (E. Colombari), deborac@foar.unesp.br (D.S.A. Colombari).

${ }^{1}$ DSAC and EC are co-senior and co-corresponding authors.
}

by (Veerasingham and Raizada, 2003)] and also an impairment of the baroreflex (Judy and Farrell, 1979).

The current standardised therapy for treating hypertension is the use of angiotensin II type I receptor (AT1R) blockers together with angiotensin converting enzyme (ACE) inhibitors (Fisher and Fadel, 2010; Grassi et al., 2010; Mann, 2003). Microinjecting angiotensin II (ANG II) centrally can target AT1Rs in cardiovascular regulating nuclei that stimulate cardiovascular pressor responses. This has been demonstrated in the rostral ventrolateral medulla (RVLM) (Ito et al., 2002; Mayorov et al., 2004), the nucleus of the solitary tract (NTS) (Casto and Phillips, 1984; Rettig et al., 1986), and the paraventricular nucleus of hypothalamus (Zhu et al., 2002).

However, ANG II can also act on the angiotensin II type 2 receptor (AT2R). Similar to AT1R, AT2R is a seven-transmembrane receptor showing over 90\% homology across humans, mice and rats (Mukoyama et al., 1993). Considering the discrete localization of AT2R and surrounding important cardiovascular control regions of the adult rodent brain (de Kloet et al., 2014), an intriguing question is the role of AT2R in cardiovascular regulation. In fact, Ichiki and colleagues have 
found that basal systolic and diastolic BP is increased in mice lacking the AT2R (Ichiki et al., 1995). However, discrepancies in the literature have been highlighted by different studies showing that basal BP was unaffected in the absence of AT2R in mice (Hein et al., 1995; Li et al., 2003). Despite these differences in basal arterial BP, all of these studies show that the pressor effects of peripheral or central ANG II infusion were significantly enhanced in AT2R knockout mice compared to wild type mice (Hein et al., 1995; Li et al., 2003). Moreover, recently, we demonstrated using the 2-kidney, 1-clip (2K1C) hypertensive rat model that increased expression of AT2R in the solitary-vagal complex [NTS/dorsal motor nucleus of the vagus (DMV); NTS/DMV] restores normal baroreflex function and attenuated hypertension (Blanch et al., 2014).

The NTS is integral to the CNS control of cardiovascular function, receiving baroreceptor and chemoreceptor afferents from the periphery and having direct and indirect pathways to the RVLM to modulate SNA and BP (Guyenet, 2006). Therefore, the possibility that AT2R may modulate the altered vagal/sympathetic tone in neurogenic hypertension has come to the forefront of our interest. In the present study, we investigated; 1) baroreflex function in conscious, non-anesthetized normotensive (NT) and SHRs; 2 ) the chronic effects of overexpressing AT2R in the NTS/DMV complex on BP and heart rate (HR) of freely moving, non-anesthetized NT and SHRs; and 3), given that studies show crosstalk between renin-angiotensin system (RAS) components and pro-inflammatory cytokines (PICs) in central cardiovascular regulatory nuclei (Guggilam et al., 2008; Shi et al., 2010; Sriramula et al., 2013), we also assessed the gene expression profile of different components of the RAS and PICs within the NTS/DVM complex in these rats.

\section{Methods}

\subsection{Animals}

Ten week old Holtzman rats and SHR were used for all experimental procedures. Post recovery, animals were housed individually with access to water and rat chow (BioBase Rat Chow, Águas Frias, Brazil) ad libitum. Room temperature was maintained at $23 \pm 2{ }^{\circ} \mathrm{C}$, humidity at $55 \pm 10 \%$ and on a 12:12 h light-dark cycle. Experimental protocols were approved by the Ethical Committee in Animal Use (CEUA) in the School of Dentistry- UNESP (Proc. CEUA 07/2011). In addition, the principles governing the care and treatment of animals, as stated in the Guide for the Care and Use of Laboratory Animals published by the National Academy of Sciences (eighth ed., 2011), were followed at all times during this study.

\subsection{Viral transduction of $A T 2 R$ in the NTS/DVM}

Adeno-associated viral vectors expressing either AT2R or eGFP (AAV2-CBA-AT2R, $3.6 \times 10^{11}$ genome copies [gc]/injection; AAV2CBA-eGFP, $1.5 \times 10^{12} \mathrm{gc} /$ injection) were used to induce the overexpression of the respective protein in the NTS/DVM. Rats were anesthetized using ketamine ( $80 \mathrm{mg} / \mathrm{kg}$ body wt., IP) and xylazine $(7 \mathrm{mg} / \mathrm{kg}$ body wt., IP) and placed in a stereotaxic head frame (David Kopf Instruments, Tujunga, CA). A partial craniotomy of the occipital bone was implemented, to expose the dorsal surface of the brainstem. A total of five microinjections were made along the entire rostral-caudal axis with a distance of $0.5 \mathrm{~mm}$ anterior from the calamus scriptorius and $0.5 \mathrm{~mm}$ lateral from the midline using a glass micropipette coupled to a Picospritzer microinjection system (Parker, Cleveland, OH, USA). The volume microinjected ( $100 \mathrm{nl} /$ site) was determined by viewing the movement of the meniscus through a binocular microscope fitted with a precalibrated eyepiece reticule with a 10 min interval between each injection. Four groups were used for the experiments as follows; 1 ) normotensive rats injected with AAV2-CBA-eGFP (NTeGFP), 2) normotensive rats injected with AAV2-CBA-AT2R (NTAT2R), 3) SHRs injected with AAV2-CBA-eGFP (SHReGFP) and 4) SHRs injected with AAV2-
CBA-AT2R (SHRATR2). Proceeding the surgical procedure, rats were administered with antibiotic IM, (benzylpenicillin - 80,000 IUs plus streptomycin - 33 mg; Pentabiótico Veterinário -Pequeno Porte, Fort Dodge Saúde Animal Ltda, Campinas, Brazil) and analgesic/anti-inflammatory SC, (ketoprofen 1\%; 0.03 ml/rat; Ketoflex, Mundo Animal, São Paulo, Brazil). AAV2-CBA-eGFP or AAV2-CBA-AT2R were constructed as described (Li et al., 2005) and these vectors elicit gene transduction primarily in neurons of all different phenotypes (Zhang et al., 2013). Our previous studies have demonstrated that AAV2-CBA-AT2R microinjected as above elicits a significant increase in AT2R protein in the NTS/DVM, based on receptor binding analyses (Blanch et al., 2014).

\subsection{Baroreflex test}

Rats were anesthetized using ketamine associated with xylazine as described previously, and a polyethylene tube (PE-10 connected to a PE-50) was inserted into the abdominal aorta through the femoral artery and another catheter was implanted into the femoral vein. Arterial and venous catheters were tunneled subcutaneously and exposed on the back of the rat. To record pulsatile arterial pressure, mean arterial pressure (MAP) and heart rate (HR) in conscious unrestrained, freely moving animals, the arterial catheter was connected to a Statham Gould (P23 Db; El Segundo, CA, USA) pressure transducer coupled to a preamplifier (model ETH-200 Bridge Bio Amplifier, Chicago, IL, USA) that was connected to a Powerlab computer data acquisition system (model Powerlab 16SP, ADInstruments, Colorado Springs CO, USA). After a baseline period of cardiovascular recordings, rats received iv injections of phenylephrine ( $5 \mu \mathrm{g} / \mathrm{kg}$, body wt.) or sodium nitroprusside (SNP; $30 \mu \mathrm{g} / \mathrm{kg}$, body wt.) to test the HR reflex responses to pressor and depressor stimuli, respectively. We analysed the one second mean HR values in response to $10 \mathrm{~mm} \mathrm{Hg}$ incremental changes in MAP, starting at $5 \mathrm{~mm} \mathrm{Hg}$ up to a maximal change of $35 \mathrm{~mm} \mathrm{Hg}$ (Blanch et al., 2014). The values were plotted, a linear regression was performed for each animal, and the slope of each linear regression was used to calculate the differences between groups.

\subsection{Radio-telemetry recording of arterial pressure}

Under ketamine associated with xylazine as described previously, a laparotomy was made to expose the descending aorta, proceeded by the implantation of a telemetry device (model TA11PA-C40; Data Sciences Int., St. Paul, MN, USA) to record arterial pressure. Dataquest 4.31 software (Data Sciences Int.) was used to analyse raw data that were expressed as MAP and HR. Recordings of arterial pressure were programmed with the following conditions; $24 \mathrm{~h} / \mathrm{d}, 5 \mathrm{~min} / \mathrm{h}$ and $20 \mathrm{~s}$ segments at a frequency of $1000 \mathrm{~Hz}$. Post surgical treatment was administered as described above.

\subsection{Histology of injection sites}

Rats were deeply anesthetized with sodium thiopental (70 mg/ $\mathrm{kg} \mathrm{b} \cdot \mathrm{wt}, \mathrm{IP}$ ) and perfused transcardially with $0.1 \mathrm{M} \mathrm{PBS}(\mathrm{pH} 7.4)$ followed by $4 \%(\mathrm{w} / \mathrm{v})$ paraformaldehyde. Brains were extracted and post fixed in $10 \%(\mathrm{w} / \mathrm{v})$ sucrose for $24 \mathrm{~h}$. Brains were snap frozen and $40 \mu \mathrm{m}$ thick sections were cut using a cryostat (Leica CM1900, Wetzlar, Germany). The sections were visualized using a Leica fluorescence microscope (Leica, DM5500 B, Wetzlar, Hesse, Germany) with the appropriate filter to visualize eGFP expression.

\section{6. $q R T-P C R$ analyses in the NTS/DMV}

Rats were deeply anesthetized with isoflurane $\left(5 \%\right.$ in $\left.100 \% \mathrm{O}_{2}\right)$, decapitated and the brains extracted for dissection. The NTS/DMV was identified using the obex and central canal as landmarks for dissection. The tissue was snap frozen at $-80{ }^{\circ} \mathrm{C}$ until required for further use. mRNA was extracted by homogenising the tissue in 2-mercaptoethanol 
(Sigma, St. Louis, USA) and isolated using a PureLink® RNA mini kit (Life technologies, Grand Island, USA). The isolated RNA was converted in cDNA using a high-capacity cDNA reverse transcription kit (Life technologies, Grand Island, USA) and samples were run in duplicate using a StepOne Real-time PCR system, Taqman Universal Gene Expression Master Mix and validated Taqman probes (Applied Biosystems, Foster City, CA, USA). Expression patterns of genes of interest were normalized to constitutively expressed 18 s (Table 1 ) and relative expression was quantified using the $2^{-\Delta \Delta \mathrm{Ct}}$ method (Livak and Schmittgen, 2001). All primers used are listed in Table 1.

\subsection{Statistical analysis}

All data are expressed as the means \pm SEM. One- or two-way ANOVA followed by Student-Newman-Keuls post hoc were used for comparisons. Differences were taken as significant at $\mathrm{P}<0.05$.

\subsection{Experimental protocols}

\subsubsection{Baroreflex function test}

In one group of rats, 4 weeks after the viral transduction, rats were implanted with two catheters: one into the abdominal aorta through the femoral artery for direct recordings of MAP and HR, and another into the femoral vein for drug administration. The next day, MAP and HR were recorded in conscious rats, followed by the analysis of baroreflex function as described in the Methods. The day following these tests, rats were deeply anesthetized, decapitated, the brains were collected for qRT-PCR analyses.

\subsubsection{Chronic recording of blood pressure in freely moving animals}

In another group of rats, following a 10-day recovery period after telemetry probe implantation, a $24 \mathrm{~h}$ basal recording of arterial pressure was taken subsequently followed by microinjection of either AAV2CBA-eGFP or AAV2-CBA-AT2R into the NTS/DMV of NT and SHR. Following this, recordings were taken once a week for a 4-week period postviral transduction (method described above). Rats were euthanized at 4 weeks post vector injection, brainstems removed, cut and mounted on slides to check the eGFP fluorescence in the NTS/DMV and indicate NTS/DMV injection site.

\section{Results}

\subsection{Identification of the viral injection sites in the NTS/DMV}

Viral microinjections of AAV2-CBA-eGFP were positively localized within the confines of the NTS/DMV complex, including the intermediate NTS (iNTS, Fig. 1A, B and E), the commissural NTS (cNTS) and DMV (Fig. 1C, D and E) with minimal spread into adjacent brain structures. Hence, the viral transduction coverage occurred along the entire

Table 1

A list of all the primers (TaqMan probes, Applied Biosciences, USA) used for RT-PCR analysis with corresponding sequence numbers. Abbreviations; Agtr1a- angiotensin type 1 receptor, Agtr2- angiotensin type 2 receptor, ACE- angiotensin converting enzyme, ACE2- angiotensin converting enzyme 2 , TNF $\alpha$ - tumour necrosis factor $\alpha$, IL-6- interleukin 6 , IL-1 $\beta$ - interleukin $1 \beta$.

\begin{tabular}{ll}
\hline Primer name & Sequence code \\
\hline Agtr1a & Rn01435427_m1 \\
Agtr2 & Rn005660677_s1 \\
Mas1 & Rn00562673_s1 \\
ACE & Rn00561094_s1 \\
ACE2 & Rn01416293_s1 \\
TNF $\alpha$ & Rn99999017_m1 \\
IL-6 & Rn01410330_m1 \\
IL-1 $\beta$ & Rn99999009_m1 \\
18s & Hs99999901_s1 \\
\hline
\end{tabular}

rostro-caudal axis of the NTS/DMV complex involved in cardiovascular regulation. These results are consistent with our previous findings (Blanch et al., 2014).

\subsection{Effects of AT2R overexpression in the NTS/DMV of NT and SHRs on the baroreflex}

The SHReGFP group showed an impaired bradycardia response compared to the normotensive groups $[-0.77 \pm 0.35 \mathrm{vs.} \mathrm{NTeGFP:}-1.71 \pm$ 0.24 and NTAT2R: $-1.98 \pm 0.52 \mathrm{bpm} / \mathrm{mm} \mathrm{Hg} ; \mathrm{F}(3,19)=3.774$; $\mathrm{P}<0.05$ ], (Fig. 2). Conversely, after AT2R transduction in the NTS/DMV in SHR, the blunted bradycardia was restored (SHRAT2R: $-1.84 \pm$ $0.30 \mathrm{bpm} / \mathrm{mm} \mathrm{Hg}$ ) to the levels observed in normotensive rats (NTAT2R: $-1.98 \pm 0.52$ and NTeGFP $-1.71 \pm 0.24 \mathrm{bmp} / \mathrm{mm} \mathrm{Hg}$ ), (Fig. 2). No significant difference was observed in the tachycardia reflex between all groups $[\mathrm{F}(3,19)=0.5557 ; \mathrm{P}=0.6506]$, (Fig. 2).

\subsection{Effect of AT2R overexpression in the NTS/DMV of NT and SHRs on MAP and $H R$}

A sustained significant difference in MAP was observed between SHR and NT groups throughout the 4 week recording period during light and dark periods $[\mathrm{F}(3,78)=192.4$ and $\mathrm{F}(3,78)=120.8$, respectively, both $\mathrm{P}<0.0001]$. However, no significant change in MAP in SHRAT2R rats was observed from week 0 to week 4 (144 \pm 6 vs. $146 \pm 3 \mathrm{~mm} \mathrm{Hg}$ respectively, $\mathrm{P}>0.05$ ) during the light period (Fig. $3 \mathrm{~A}$ ) and (148 \pm 6 vs. $148 \pm 5 \mathrm{~mm} \mathrm{Hg}$ respectively, $\mathrm{P}>0.05)$ during the dark period (Fig. 3B), and no difference was observed compared to the SHReGFP group (light period: $139 \pm 3$ and dark period: $146 \pm$ $4 \mathrm{~mm} \mathrm{Hg}$, at 4 weeks post virus transduction). A similar finding was observed in NTAT2R rats from week 0 to week 4 (95 $\pm 2 \mathrm{vs.} 97 \pm 6 \mathrm{~mm} \mathrm{Hg}$, respectively, $\mathrm{P}>0.05)$ in the light period (Fig. $3 \mathrm{~A})$ and $(104 \pm 3 \mathrm{vs}$. $109 \pm 7$, respectively, $\mathrm{P}>0.05$ ) in the dark period (Fig. 3B).

HR was very variable during the 4 -week recording period. There were no major changes in HR after eGFP and AT2R overexpression in the NTS/DMV complex of all groups of rats when comparing their levels from week 0 to week 4 during the light period and at matched time points (Fig. 3C). However, in the dark period, there was a minor but significant decrease in the HR of SHRAT2R group compared to the NTAT2R group from 1 to 2 weeks post-viral transduction into the NTS/DMV complex $[\mathrm{F}(3,74)=22.84 ; \mathrm{P}<0.0001]$ (Fig. $3 \mathrm{D}$ ); suggesting the chronic bradycardic potency of overexpressing AT2R in the NTS/DMV.

3.4. Effects of AT2R overexpression in the NTS/DMV of NT and SHRs on gene expression levels of RAS components and PICs in the NTS/DMV

As expected, the successful microinjection of AAV2-AT2R was confirmed by quantifying that AT2R mRNA expression was significantly higher in the NTAT2R and SHRAT2R groups compared to the NTeGFP and SHReGFP groups $[F(3,16)=5.848 ; \mathrm{P}=0.007]$; (Fig. 4A). The increased levels of AT1R mRNA in the SHReGFP group were unchanged after AT2R transduction in the NTS/DMV and AT1R mRNA levels of the hypertensive groups were higher compared to both of the NT groups $[\mathrm{F}(3,14)=18.800 ; \mathrm{P}<0.001]$, (Fig. 4B). No significant change was observed in Mas receptor mRNA levels between all groups $[\mathrm{F}(3,16)=$ 1.373; P = 0.287], (Fig. 4C). AT2R transduction in the NTS/DMV complex of SHR decreased the preexisting elevated levels of ACE mRNA found in the SHReGFP group to values comparable to the NT groups $[F(3,15)=10.125 ; \mathrm{P}<0.001]$, (Fig. 4D). Conversely, ACE2 mRNA levels were increased in the SHRAT2R group compared to all groups $[F(3,16)=6.059 ; \mathrm{P}=0.006]$; (Fig. 4E). Calculating the ratio of ACE/ ACE2 mRNA, we found that after transduction of AT2R in the NTS/ DMV of SHR, the higher ACE/ACE2 ratio observed in SHReGFP was totally abolished $[\mathrm{F}(3,15)=42.016$; $\mathrm{P}<0.001]$, (Fig. 4F).

The SHReGFP group expressed a significantly higher level of PIC mRNA levels compared to the NT groups, and AT2R transduction in 

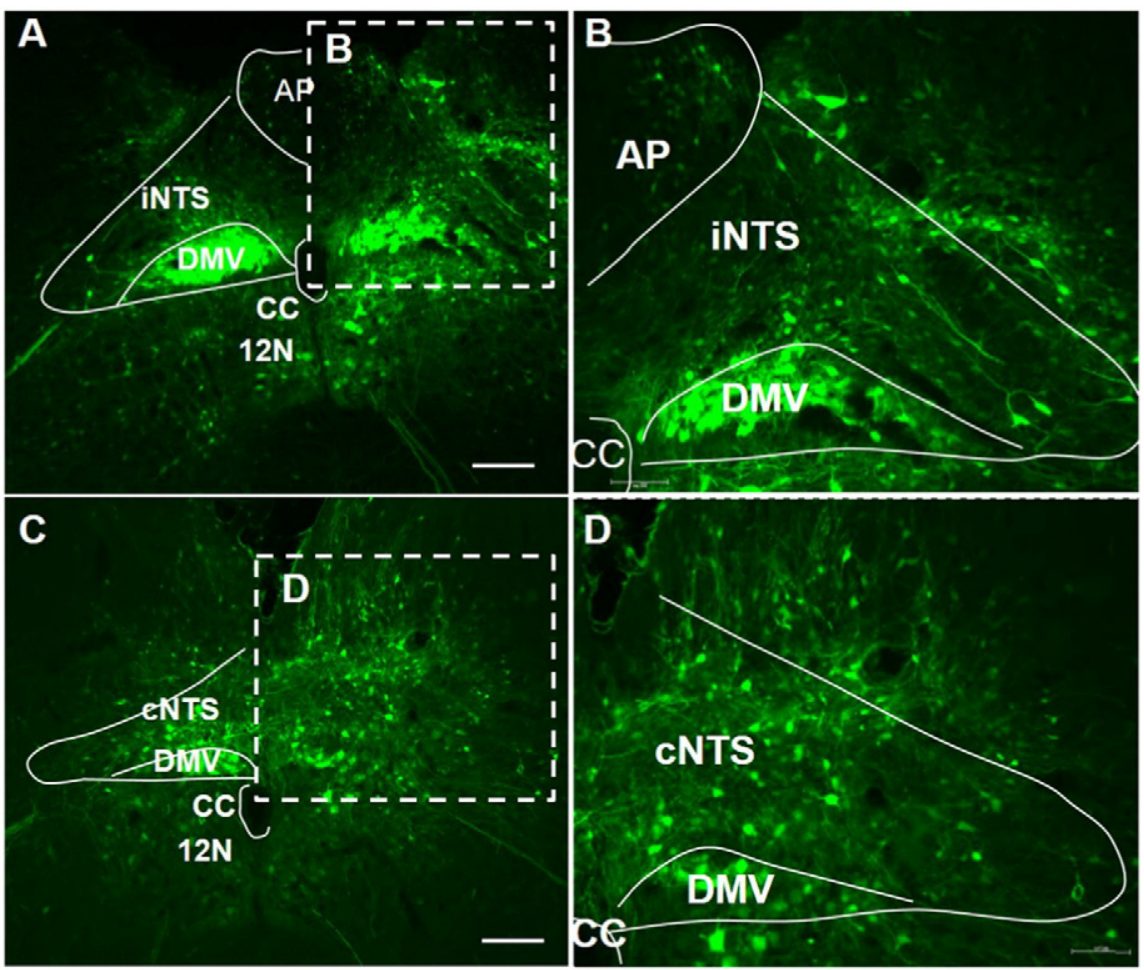

$\mathbf{E}$

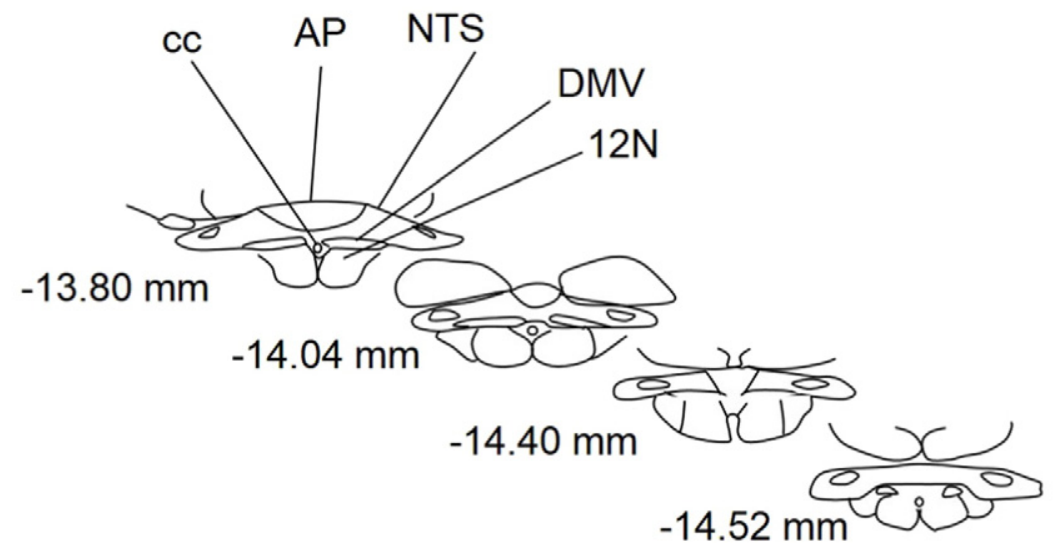

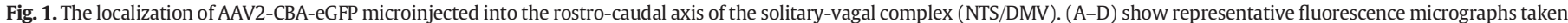

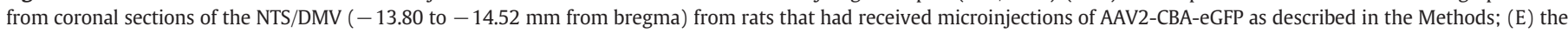

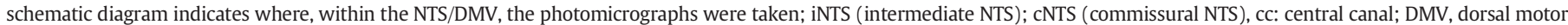
nucleus of the vagus; $12 \mathrm{~N}$ : hypoglossus nucleus; AP, area postrema. Schematic diagrams adapted from Paxinos and Watson (1986). Scale bar 100 $\mu$ m.

the NTS/DMV of SHR decreased mRNA levels of TNF $\alpha[F(3,15)=$ 23.769; $\mathrm{P}<0.001]$, IL-6 $[\mathrm{F}(3,14)=19.461 ; \mathrm{P}<0.001)$ and IL-1 $\beta$ $[\mathrm{F}(3,15)=9.486 ; \mathrm{P}<0.001]$, (Fig. $5 \mathrm{~A}-\mathrm{C}$ ).

\section{Discussion}

In this study the following findings were obtained when overexpressing AT2R in the NTS/DMV complex of SHR; first, that a significant improvement in the baroreflex response was observed at 4 weeks post AT2R transfection; second, that mRNA levels of ACE2 was significantly increased, with a synergistic decrease in ACE mRNA levels; third, that corresponding reductions in PICs were synergistically reduced and fourth, that MAP was not significantly altered, but a transient reduction in HR during the dark period was observed. The data suggest beneficial modulatory effect AT2R overexpression in the NTS/DMV complex on the cardiovascular system. AT2R transduction in the NTS/ DMV complex was effective since the levels of its mRNA significantly increased compared to their corresponding basal endogenous levels. Furthermore, the specificity of targeting the NTS/DMV complex via viral vector transfection was confirmed by histological analysis showing localized expression of eGFP within the boundaries of the solitary-vagal complex.

In the present study, baroreflex responses were significantly improved in SHRAT2R rats compared to SHReGFP rats. The mechanism involved in the restoration of the baroreflex remains to be elucidated; however, a possibility may involve the influence of ACE2. We observed that ACE2 mRNA was increased in the NTS/DMV complex of SHRAT2R rats. In fact, ACE2 overexpression in the NTS of SHR has been shown to improve the baroreflex (Yamazato et al., 2011; Yamazato et al., 2009). ACE2 has high catalytic activity converting ANG II to angiotensin (Ang) 1-7 (Fraga-Silva et al., 2013), which has been shown to act in the NTS to increase baroreflex sensitivity (Chaves et al., 2000; Diz et al., 2008). Thus, it is plausible to consider that the increase in baroreflex sensitivity observed in the present study in SHRAT2R might be partly 


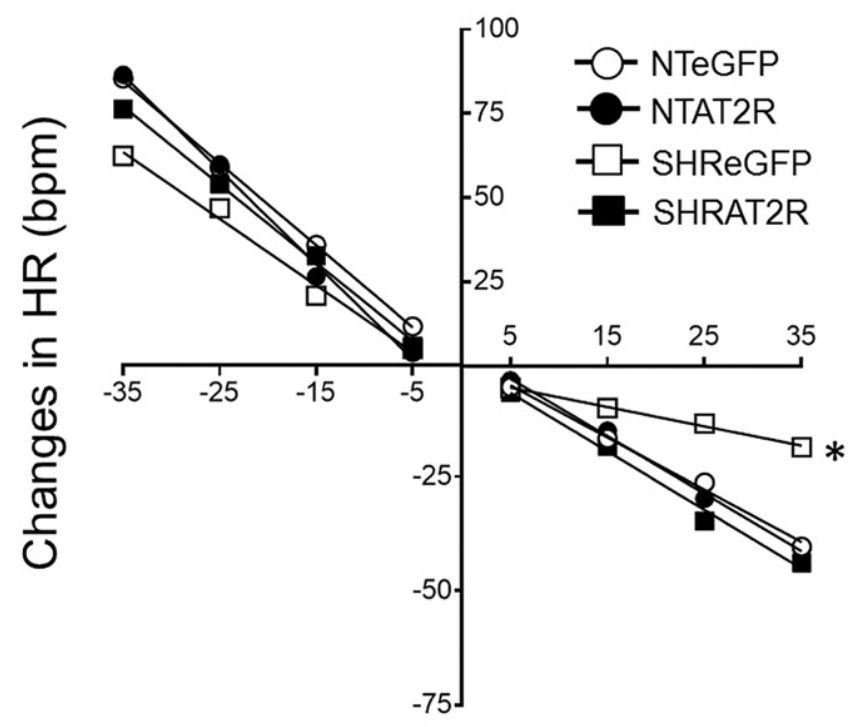

Changes in MAP $(\mathrm{mmHg})$

Fig. 2. Improved baroreflex response in hypertensive rats overexpressing AT2R in the solitary-vagal complex (NTS/DMV). Four weeks after the overexpression of AAV2-CBAeGFP or AAV2-CBA-AT2R in the NTS/DMV of normotensive (NT) and spontaneously hypertensive rats (SHR), the corresponding change in heart rate (HR) was analysed when mean arterial pressure (MAP) was altered by boluses of phenylephrine (pressor) or sodium nitroprusside (depressor). The results are presented as mean \pm SEM; NTeGFP, $n=7$; NTAT2R, $n=4$; SHReGFP, $n=5$; SHRAT2R, $n=7$. ${ }^{*}<0.05$ vs. all groups.

due to an increased level of ACE2 in the NTS/DMV complex, and thus activation of the ACE2/Ang 1-7/Mas receptor pathway. We also observed that the higher ACE levels found in the SHReGFP group were decreased in the NTS/DMV complex in the SHRAT2R group. ACE also metabolizes Ang 1-7 (Chappell et al., 1998), thus the decreased levels of ACE in the NTS/DMV of SHRAT2R rats found in this study could also permit an increase in Ang 1-7 levels. Although, the molecular mechanisms involved the regulation of ACE2 and ACE expression in the NTS/DMV by AT2R levels are yet to be determined, it has been demonstrated that the lower expression levels and the activity of ACE2 in kidney cortex of obese Zucker rats were restored after 2 weeks treatment with CGP42112A, an AT2R agonist (Ali et al., 2013). Furthermore, the nonpeptide AT2R agonist Compound 21 (C21) reversed the increase in pulmonary ACE and decrease in pulmonary ACE2 occurring in rats with pulmonary hypertension induced by monocrotaline treatment (Bruce et al., 2015). Therefore, it seems that the activation of AT2R leads to an increase in ACE2 and a decrease in ACE expression, similar to that observed in the present study.

Inhibiting PICs via intracerebroventricular infusion of pentoxifylline significantly reduces hypothalamic AT1R and ACE protein levels, suggesting cross-talk between PICs and the RAS (Kang et al., 2008). Conversely, peripheral treatment with C21 decreased the higher PIC levels in the kidney of renovascular hypertensive rats (Matavelli et al., 2011), a result similar to the one observed in the present study where the higher PIC levels in the solitary-vagal complex were reduced by AT2R overexpression. Therefore, considering that IL- 6 microinjection in the NTS reduces baroreflex bradycardia (Takagishi et al., 2010), the reduction of IL- 6 mRNA levels after overexpressing AT2R in the solitary-vagal complex could also account for the improvement in the baroreflex response observed in the SHRAT2R group.

The AT2R and Mas receptors as well as ACE2 are collectively known as the "protective axis" of the RAS, counteracting the effects of AT1R (Iwai and Horiuchi, 2009). Indeed, recently published data from our laboratory demonstrated that overexpressing AT2R in the solitary-vagal complex of 2K1C hypertensive rats slows the development of hypertension in secondary hypertensive models (Blanch et al., 2014). This effect

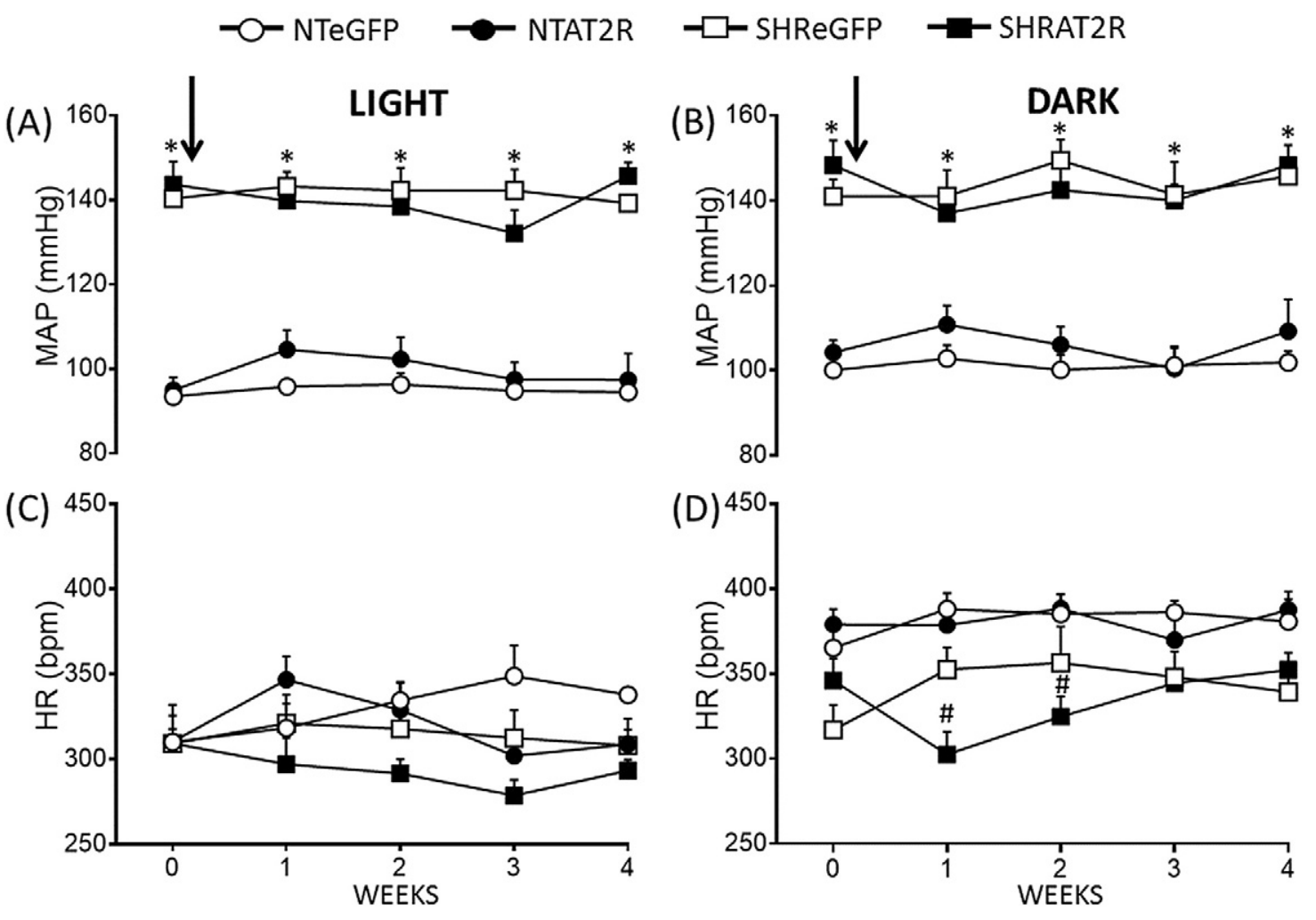

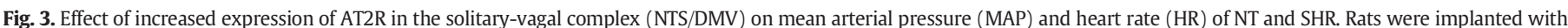

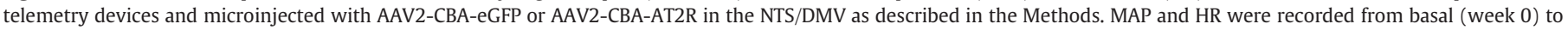

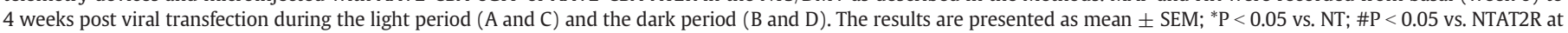
matched time points; $n=5$ for all groups. Arrows indicate time of viral microinjection into the NTS/DMV. 

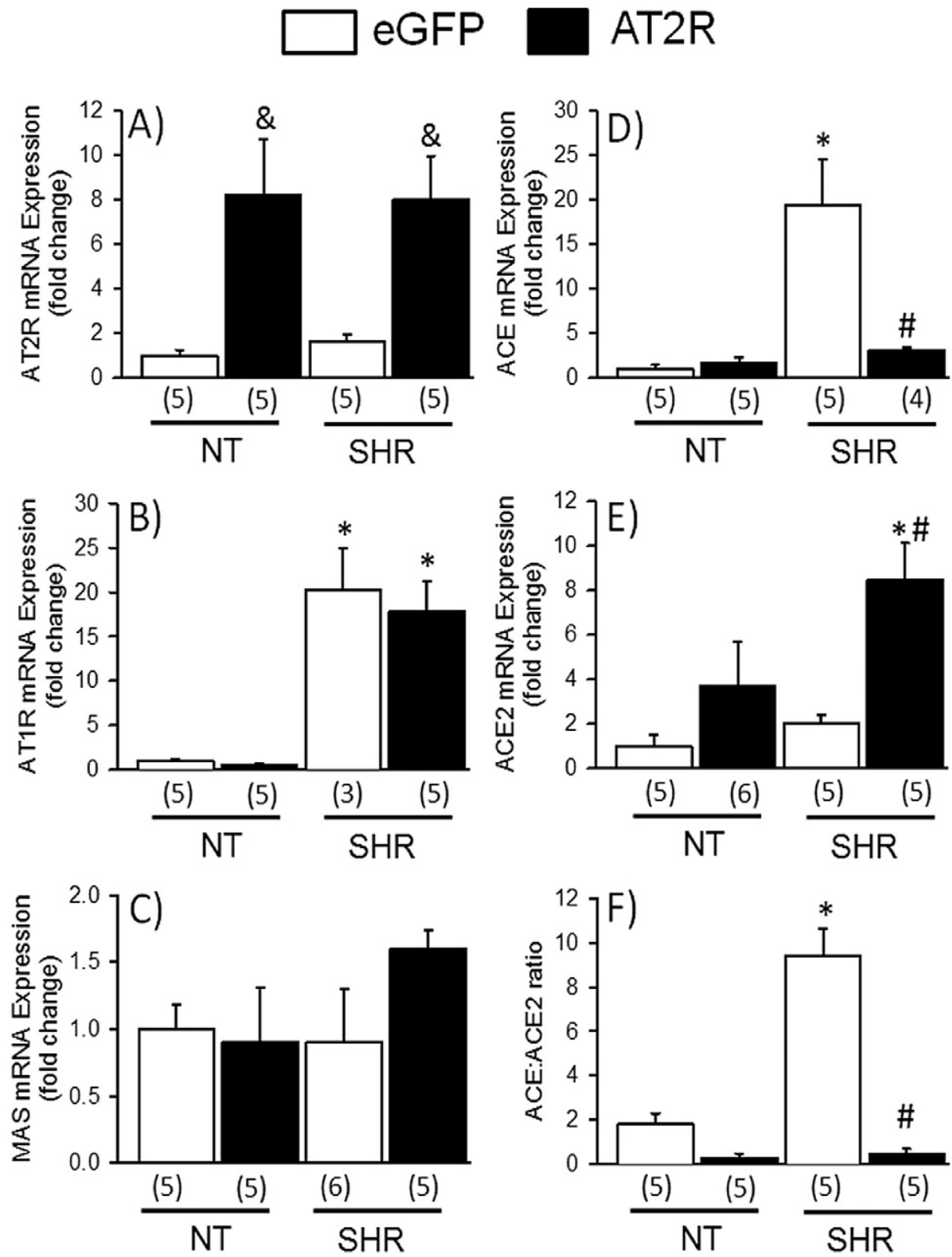

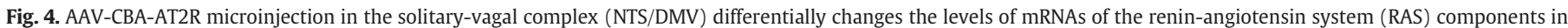

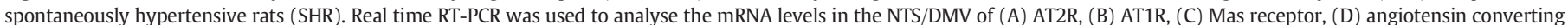

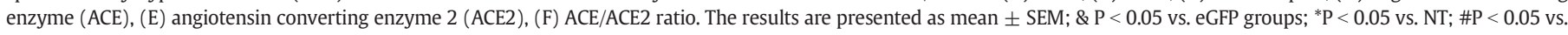
SHReGFP. The number of animals are between parenthesis; NT, normotensive.

was associated with a decreased low frequency of the systolic pressure and a concomitant increase in ACE2 mRNA levels compared to $2 \mathrm{~K} 1 \mathrm{C}$ rats overexpressing eGFP (Blanch et al., 2014). However, in the present study we demonstrated that similar viral vector-mediated overexpression of AT2R in the solitary-vagal complex was not able to reverse the established hypertension in SHR. Possible explanations for $\mathrm{BP}$ being significantly reduced in the $2 \mathrm{~K} 1 \mathrm{C}$ model of hypertension while remaining unaltered in SHR might be due to several factors. First, lesion studies show that ablating the excessive excitatory pathways emanating from the commissural NTS to the RVLM in SHR rats is not sufficient to permanently decrease BP (Sato et al., 2001). However, simultaneously ablating the commissural NTS and the anteroventral third ventricle region in the forebrain chronically reduces hypertension (Moreira et al., 2009). This suggest that in the SHR model, hypertension is dependent on several mechanisms involving multiple cardiovascular areas of the brain. Targeting several brain regions simultaneously with AT2R overexpression might be necessary to yield a greater physiological effect on BP in SHR. For instance, Gao et al. (2008) blocked the increase in nocturnal arterial pressure and a reduction in noradrenaline excretion in conscious normotensive rats overexpressing AT2R in the RVLM, the main brain area containing the pre-motor sympathetic neurons. Second, it has been shown that I.V. infusion of C21 (AT2R agonist) in SHRs requires a combined treatment with low dose AT1R blocker candesartan to unmask and augment the BP-lowering effect of AT2R (Bosnyak et al., 2010). Recently published data revealed that AT2R vasodilator effects are unmasked by the concomitant use of ACE inhibitors in SHRs in vivo (Brouwers et al., 2013). Hence, it is possible to speculate that the lack of a potent AT1R blocker or ACE inhibitor concomitantly administered with AT2R may initiate a physiological change in BP, suggesting that within the NTS/DMV complex AT2R alone is unable to alter the pre-existing BP set point in SHR. Translationally, AT2R activation/overexpression may be used as a 


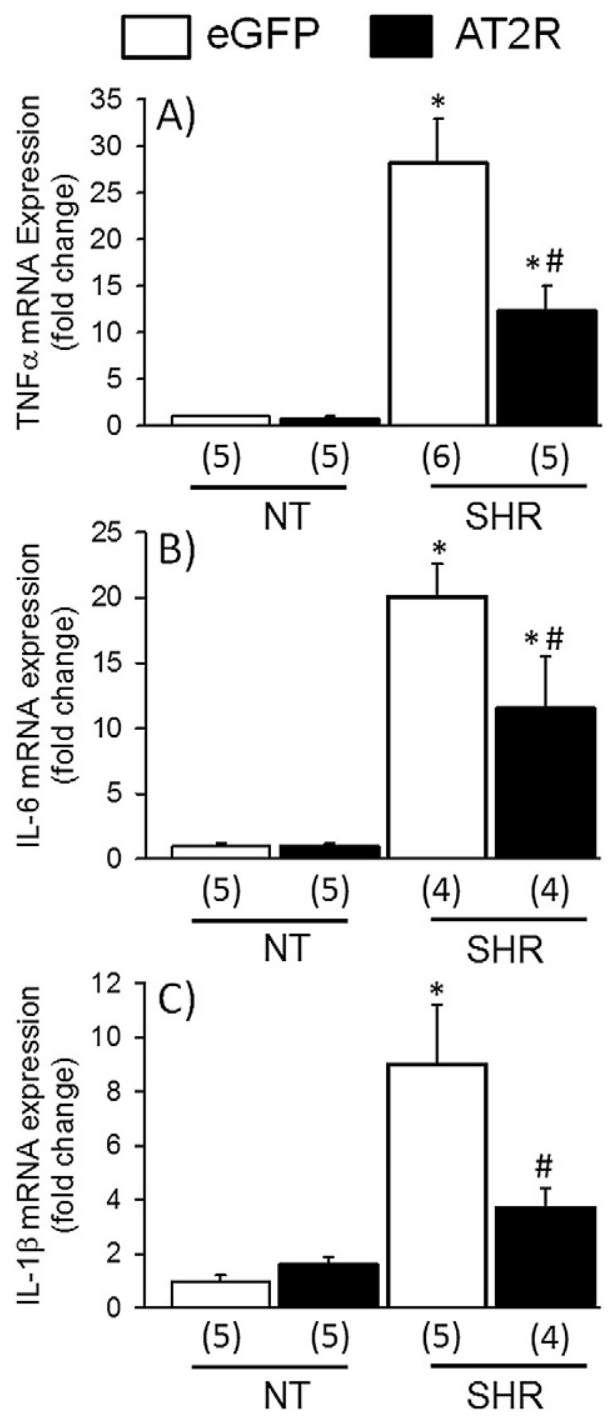

Fig. 5. AAV-CBA-AT2R microinjection in the solitary-vagal complex (NTS/DMV) decreases the mRNA levels of proinflammatory cytokines (PICs) in spontaneously hypertensive rats (SHR). Real time RT-PCR was used to analyse the mRNA levels in the NTS/DMV of (A) tumour necrosis factor $\alpha$ (TNF $\alpha$ ), (B) interleukin-6 (IL-6) and (C) interleukin-1 $\beta$ (IL$1 \beta)$. The results are presented as mean $\pm \mathrm{SEM}$; ${ }^{*} \mathrm{P}<0.05$ vs. NT; \#P $<0.05$ vs. SHReGFP. The number of animals are between parenthesis; NT, normotensive.

concomitant therapy and not as a monotherapy for the treatment of hypertension.

\section{Conclusion}

Chronic elevation of arterial pressure can change baroreflex function as observed in different animal models of hypertension (Blanch et al., 2014; Judy and Farrell, 1979), including in the SHR, and an impairment of baroreflex function has been shown to be a predictor of cardiac mortality (La Rovere et al., 1998; La Rovere et al., 2013). Therefore, impaired baroreflex function should also be a target for neurogenic hypertension treatment. To this end, the present data, which is the first study to overexpress AT2R in the NTS/DMV of SHR, suggest a cardiovascular role for the AT2R in rectifying the impaired baroreflex response typically seen in SHR, providing evidence of a physiological effect of AT2R in cardiovascular regulation.

\section{Conflict of interest}

None.

\section{Acknowledgments}

The authors thank Reginaldo C. Queiroz, Silas P. Barbosa and Silvia Fóglia for expert technical assistance, Silvana A. D. Malavolta and Carla D. Alencar for secretarial assistance, Adriano P. Oliveira e Ana V. Oliveira for animal care. This research was supported by Conselho Nacional de Pesquisa (CNPq 473108/2011-9 and 304918/2011-3), Fundação de Amparo à Pesquisa do Estado de São Paulo (FAPESP 2011/50770-1; 2012/23546-6; 2013/50121-9) and Programa Nacional de Pós Doutorado/Coordenação de Aperfeiçoamento de Pessoal de Nível Superior (PNPD/CAPES 2053/2013), and NIH grant HL-076803.

\section{References}

Ali, Q., Wu, Y., Hussain, T., 2013. Chronic AT2 receptor activation attenuates renal AT1 receptor function and blood pressure in obese Zucker rats. Kidney Int. 84, 931-939.

Blanch, G.T., Freiria-Oliveira, A.H., Speretta, G.F., Carrera, E.J., Li, H., Speth, R.C., Colombari, E., Sumners, C., Colombari, D.S., 2014. Increased expression of angiotensin II type 2 receptors in the solitary-vagal complex blunts renovascular hypertension. Hypertension 64, 777-783.

Bosnyak, S., Welungoda, I.K., Hallberg, A., Alterman, M., Widdop, R.E., Jones, E.S., 2010. Stimulation of angiotensin AT2 receptors by the non-peptide agonist, compound 21 , evokes vasodepressor effects in conscious spontaneously hypertensive rats. Br. J. Pharmacol. 159, 709-716.

Brouwers, S., Smolders, I., Massie, A., Dupont, A.G., 2013. Angiotensin II type 2 receptormediated and nitric oxide-dependent renal vasodilator response to compound 21 unmasked by angiotensin-converting enzyme inhibition in spontaneously hypertensive rats in vivo. Hypertension 62, 920-926.

Bruce, E., Shenoy, V., Rathinasabapathy, A., Espejo, A., Horowitz, A., Oswalt, A., Francis, J., Nair, A., Unger, T., Raizada, M.K., Steckelings, U.M., Sumners, C., Katovich, M.J., 2015. Selective activation of angiotensin AT2 receptors attenuates progression of pulmonary hypertension and inhibits cardiopulmonary fibrosis. Br. J. Pharmacol. 172, 2219-2231.

Casto, R., Phillips, M.I., 1984. Mechanism of pressor effects by angiotensin in the nucleus tractus solitarius of rats. Am. J. Phys. 247, R575-R581.

Chappell, M.C., Pirro, N.T., Sykes, A., Ferrario, C.M., 1998. Metabolism of angiotensin-(1-7) by angiotensin-converting enzyme. Hypertension 31, 362-367.

Chaves, G.Z., Caligiorne, S.M., Santos, R.A., Khosla, M.C., Campagnole-Santos, M.J., 2000. Modulation of the baroreflex control of heart rate by angiotensin-(1-7) at the nucleus tractus solitarii of normotensive and spontaneously hypertensive rats. J. Hypertens. 18, 1841-1848.

de Kloet, A.D., Wang, L., Ludin, J.A., Smith, J.A., Pioquinto, D.J., Hiller, H., Steckelings, U.M., Scheuer, D.A., Sumners, C., Krause, E.G., 2014. Reporter mouse strain provides a novel look at angiotensin type-2 receptor distribution in the central nervous system. Brain Struct. Funct.

Diz, D.I., Garcia-Espinosa, M.A., Gegick, S., Tommasi, E.N., Ferrario, C.M., Ann Tallant, E., Chappell, M.C., Gallagher, P.E., 2008. Injections of angiotensin-converting enzyme 2 inhibitor MLN4760 into nucleus tractus solitarii reduce baroreceptor reflex sensitivity for heart rate control in rats. Exp. Physiol. 93, 694-700.

Fisher, J.P., Fadel, P.J., 2010. Therapeutic strategies for targeting excessive central sympathetic activation in human hypertension. Exp. Physiol. 95, 572-580.

Fraga-Silva, R.A., Ferreira, A.J., Dos Santos, R.A., 2013. Opportunities for targeting the angiotensin-converting enzyme 2/angiotensin-(1-7)/mas receptor pathway in hypertension. Curr. Hypertens. Rep. 15, 31-38.

Gao, L., Wang, W., Wang, W., Li, H., Sumners, C., Zucker, I.H., 2008. Effects of angiotensin type 2 receptor overexpression in the rostral ventrolateral medulla on blood pressure and urine excretion in normal rats. Hypertension 51, 521-527.

Grassi, G., Quarti-Trevano, F., Brambilla, G., Seravalle, G., 2010. Blood pressure control in resistant hypertension: new therapeutic options. Expert. Rev. Cardiovasc. Ther. 8, 1579-1585.

Guggilam, A., Patel, K.P., Haque, M., Ebenezer, P.J., Kapusta, D.R., Francis, J., 2008. Cytokine blockade attenuates sympathoexcitation in heart failure: cross-talk between nNOS, AT-1R and cytokines in the hypothalamic paraventricular nucleus. Eur. J. Heart Fail. $10,625-634$.

Guyenet, P.G., 2006. The sympathetic control of blood pressure. Nat.Rev. Neurosci. 7, 335346.

Hein, L., Barsh, G.S., Pratt, R.E., Dzau, V.J., Kobilka, B.K., 1995. Behavioural and cardiovascular effects of disrupting the angiotensin II type-2 receptor in mice. Nature 377 , 744-747.

Ichiki, T., Labosky, P.A., Shiota, C., Okuyama, S., Imagawa, Y., Fogo, A., Niimura, F., Ichikawa, I., Hogan, B.L., Inagami, T., 1995. Effects on blood pressure and exploratory behaviour of mice lacking angiotensin II type-2 receptor. Nature 377, 748-750.

Ito, S., Komatsu, K., Tsukamoto, K., Kanmatsuse, K., Sved, A.F., 2002. Ventrolateral medulla AT1 receptors support blood pressure in hypertensive rats. Hypertension 40, 552-559.

Iwai, M., Horiuchi, M., 2009. Devil and angel in the renin-angiotensin system: ACE-angiotensin II-AT1 receptor axis vs. ACE2-angiotensin-(1-7)-Mas receptor axis. Hypertens. Res. 32, 533-536.

Judy, W.V., Farrell, S.K., 1979. Arterial baroreceptor reflex control of sympathetic nerve activity in the spontaneously hypertensive rat. Hypertension 1, 605-614. 
Kang, Y.M., Ma, Y., Elks, C., Zheng, J.P., Yang, Z.M., Francis, J., 2008. Cross-talk between cytokines and renin-angiotensin in hypothalamic paraventricular nucleus in heart failure: role of nuclear factor-kappaB. Cardiovasc. Res. 79, 671-678.

La Rovere, M.T., Bigger Jr., J.T., Marcus, F.I., Mortara, A., Schwartz, P.J., 1998. Baroreflex sensitivity and heart-rate variability in prediction of total cardiac mortality after myocardial infarction. ATRAMI (autonomic tone and reflexes after myocardial infarction) investigators. Lancet 351, 478-484.

La Rovere, M.T., Pinna, G.D., Maestri, R., Sleight, P., 2013. Clinical value of baroreflex sensitivity. Neth. Hear. J. 21, 61-63.

Li, Z., Iwai, M., Wu, L., Shiuchi, T., Jinno, T., Cui, T.X., Horiuchi, M., 2003. Role of AT2 receptor in the brain in regulation of blood pressure and water intake. Am. J. Physiol. Heart Circ. Physiol. 284, H116-H121.

Li, H.W., Gao, Y.X., Raizada, M.K., Sumners, C., 2005. Intronic enhancement of angiotensin II type 2 receptor transgene expression in vitro and in vivo. Biochem. Biophys. Res. Commun. 336, 29-35.

Livak, K.J., Schmittgen, T.D., 2001. Analysis of relative gene expression data using realtime quantitative PCR and the 2(-Delta Delta C(T)) method. Methods 25, 402-408.

Mann, S.J., 2003. Neurogenic essential hypertension revisited: the case for increased clinical and research attention. Am. J. Hypertens. 16, 881-888.

Matavelli, L.C., Huang, J., Siragy, H.M., 2011. Angiotensin AT2 receptor stimulation inhibits early renal inflammation in renovascular hypertension. Hypertension 57, 308-313.

Mayorov, D.N., Head, G.A., De, M.R., 2004. Tempol attenuates excitatory actions of angiotensin II in the rostral ventrolateral medulla during emotional stress. Hypertension 44, 101-106.

Moreira, T.S., Takakura, A.C., Colombari, E., Menani, J.V., 2009. Antihypertensive effects of central ablations in spontaneously hypertensive rats. Am.J.Physiol Regul.Integr.Comp. Physiol. 296, R1797-R1806.

Mukoyama, M., Nakajima, M., Horiuchi, M., Sasamura, H., Pratt, R.E., Dzau, V.J., 1993. Expression cloning of type 2 angiotensin II receptor reveals a unique class of seventransmembrane receptors. J. Biol. Chem. 268, 24539-24542.

Paxinos, G., Watson, C., 1986. The Rat Brain in Stereotaxic Coordinates. second ed. Academic Press, Inc, San Diego.

Primatesta, P., Poulter, N.R., 2006. Improvement in hypertension management in England: results from the Health Survey for England 2003. J. Hypertens. 24, 1187-1192.
Rettig, R., Healy, D.P., Printz, M.P., 1986. Cardiovascular effects of microinjections of angiotensin II into the nucleus tractus solitarii. Brain Res. 364, 233-240.

Sato, M.A., Menani, J.V., Lopes, O.U., Colombari, E., 2001. Lesions of the commissural nucleus of the solitary tract reduce arterial pressure in spontaneously hypertensive rats. Hypertension 38, 560-564

Shi, P., Diez-Freire, C., Jun, J.Y., Qi, Y., Katovich, M.J., Li, Q., Sriramula, S., Francis, J., Sumners, C., Raizada, M.K., 2010. Brain microglial cytokines in neurogenic hypertension. Hypertension 56, 297-303.

Sriramula, S., Cardinale, J.P., Francis, J., 2013. Inhibition of TNF in the brain reverses alterations in RAS components and attenuates angiotensin II-induced hypertension. PLoS. One 8, e63847.

Takagishi, M., Waki, H., Bhuiyan, M.E., Gouraud, S.S., Kohsaka, A., Cui, H., Yamazaki, T. Paton, J.F., Maeda, M., 2010. IL-6 microinjected in the nucleus tractus solitarii attenuates cardiac baroreceptor reflex function in rats. Am. J. Physiol. Regul. Integr. Comp. Physiol. 298, R183-R190.

Trippodo, N.C., Frohlich, E.D., 1981. Similarities of genetic (spontaneous) hypertension. Man and rat. Circ. Res. 48, 309-319.

Veerasingham, S.J., Raizada, M.K., 2003. Brain renin-angiotensin system dysfunction in hypertension: recent advances and perspectives. Br. J. Pharmacol. 139, 191-202.

Yamazato, Y., Ferreira, A.J., Hong, K.H., Sriramula, S., Francis, J., Yamazato, M., Yuan, L., Bradford, C.N., Shenoy, V., Oh, S.P., Katovich, M.J., Raizada, M.K., 2009. Prevention of pulmonary hypertension by angiotensin-converting enzyme 2 gene transfer. Hypertension 54, 365-371.

Yamazato, M., Ferreira, A.J., Yamazato, Y., Diez-Freire, C., Yuan, L., Gillies, R., Raizada, M.K. 2011. Gene transfer of angiotensin-converting enzyme 2 in the nucleus tractus solitarius improves baroreceptor heart rate reflex in spontaneously hypertensive rats. J. Renin-Angiotensin-Aldosterone Syst. 12, 456-461.

Zhang, Y., Gao, Y., Speth, R.C., Jiang, N., Mao, Y., Sumners, C., Li, H., 2013. Adenoviral and adeno-associated viral vectors-mediated neuronal gene transfer to cardiovascular control regions of the rat brain. Int. J. Med. Sci. 10, 607-616.

Zhu, G.Q., Patel, K.P., Zucker, I.H., Wang, W., 2002. Microinjection of ANG II into paraventricular nucleus enhances cardiac sympathetic afferent reflex in rats. Am. J. Physiol. Heart Circ. Physiol. 282, H2039-H2045. 